\section{Case Reports in Gastroenterology}

Case Rep Gastroenterol 2017;11:305-311

DOI: $10.1159 / 000475752$

Publisned onime: TViay 17, 2017 (c) 2017 The Author(s)

Published by S. Karger AG, Basel www.karger.com/crg

This article is licensed under the Creative Commons Attribution-NonCommercial 4.0 International License (CC BY-NC) (http://www.karger.com/Services/OpenAccessLicense) Usage and distribution for commercial purposes requires written permission.

\title{
Successful Treatment for Chronic Hepatitis C-Autoimmune Hepatitis Overlap Syndrome due to Daclatasvir and Asunaprevir
}

\author{
Ayumi Sugiura $^{a}$ Shuichi Wada ${ }^{a}$ Hiromitsu Mori ${ }^{a}$ Takefumi Kimura ${ }^{a}$ \\ Yoshiaki Matsuda $^{a}$ Naoki Tanaka ${ }^{b}$ Eiji Tanaka ${ }^{c} \quad K^{2}$ Kendo Kiyosawa ${ }^{a}$ \\ aDepartment of Internal Medicine, Division of Gastroenterology, Nagano Red Cross \\ Hospital, Nagano, Japan; ${ }^{b}$ Department of Metabolic Regulation, Shinshu University \\ Graduate School of Medicine, Matsumoto, Japan; 'Department of Internal Medicine, \\ Division of Gastroenterology, Shinshu University School of Medicine, Matsumoto, Japan
}

\section{Keywords}

Chronic hepatitis C-autoimmune hepatitis overlap syndrome - Direct-acting antivirals .

Hepatitis $C$ virus · Autoimmunity · Interferon

\begin{abstract}
Persistent hepatitis $\mathrm{C}$ virus (HCV) infection may induce autoimmune diseases and chronic hepatitis $C$ is sometimes accompanied by autoimmune hepatitis (AIH). However, we are worried about the treatment for chronic hepatitis C-AIH overlap syndrome because interferonbased antiviral therapies may enhance autoimmunity and immunosuppressive corticosteroid administration may promote viral replication. Here, we report a patient having chronic hepatitis C-AIH overlap syndrome treated with the direct-acting antivirals (DAA), daclatasvir and asunaprevir. A 50-year-old man was referred to our hospital because of positive anti-HCV antibody and liver dysfunction at a health checkup. Blood tests showed increased immunoglobulin G (IgG) and a high titer of antinuclear antibody (ANA) in addition to elevated serum




\section{Case Reports in \\ Gastroenterology}

Case Rep Gastroenterol 2017;11:305-311

(c) 2017 The Author(s). Published by S. Karger AG, Basel www.karger.com/crg

Sugiura et al.: Successful Treatment for Chronic Hepatitis C-Autoimmune Hepatitis Overlap Syndrome due to Daclatasvir and Asunaprevir

alanine aminotransferase (ALT) and HCV-RNA. Infiltration of lymphocytes and plasma cells in Glisson's capsule and severe interface hepatitis were observed in biopsied specimen, which fulfilled the criteria of AIH. We first started oral corticosteroid administration, and serum ALT levels decreased once but elevated again. We commenced daclatasvir and asunaprevir (60 and $200 \mathrm{mg} /$ day, respectively) and serum HCV-RNA became negative after 6 weeks. Adverse effects were not found during the DAA treatment, and serum ALT, IgG, and ANA were significantly decreased. Corticosteroid could be tapered and stopped, but no recurrence occurred. DAA treatment appears to be effective and safe for the patients with chronic hepatitis C-AIH overlap syndrome.

(C) 2017 The Author(s)

Published by S. Karger AG, Basel

\section{Introduction}

Persistent hepatitis C virus (HCV) infection is associated with autoimmune diseases and lymphoproliferative disorders. The prevalence of positive non-organ-specific autoantibodies is reported to be $25-80 \%$ in HCV-infected patients, which is higher than in hepatitis B virus (HBV)-infected patients (10-30\%) [1]. The positive rate of antinuclear antibodies (ANA) in HCV-infected patients is also higher than in HBV-infected patients [1]. It is well known that autoimmune thyroiditis and Sjögren syndrome are typical extrahepatic manifestations of HCV infection [2]. Additionally, mice carrying the gene encoding HCV envelop protein showed sialadenitis histologically resembling Sjögren syndrome [3], suggesting that HCV itself may disrupt the immune system.

Chronic hepatitis $\mathrm{C}$ is often accompanied by autoimmune hepatitis (AIH), designated as chronic hepatitis C-AIH overlap syndrome. Since excessive immune response against HCV may promote autoimmunity, it is reasonable to consider HCV eradiation by interferon (IFN) administration. However, IFN treatment to chronic hepatitis C-AIH overlap syndrome was reported to activate the immune system, leading to severe exacerbation of AIH [4]. On the other hand, immunosuppressive agents may enhance HCV replication and worsen HCVinduced hepatitis. Therefore, we are in a dilemma about the treatment of chronic hepatitis CAIH overlap syndrome.

Recently, direct-acting antivirals (DAA) can be used for chronic hepatitis $\mathrm{C}$ patients in Japan. We report a patient with chronic hepatitis C-AIH overlap syndrome who was successfully treated with DAA.

\section{Case Presentation}

A 50-year-old man was referred to our hospital because of positive anti-HCV antibody and increased serum transaminase levels at a health checkup. He had consumed ethanol ( 40 $\mathrm{g}$ /day) for 30 years, but had no history of receiving blood transfusion. He had undergone laparoscopic cholecystectomy 10 years earlier. His height was $176 \mathrm{~cm}$, body weight was 74 $\mathrm{kg}$ (body mass index: $23.9 \mathrm{~kg} / \mathrm{m}^{2}$ ), blood pressure was $130 / 85 \mathrm{mmHg}$, and pulse rate was $84 /$ min. No vascular spider, red palm, gynecomastia, edema, or hepatosplenomegaly were observed. Blood examinations exhibited elevated aspartate and alanine aminotransferase 


\section{Case Reports in \\ Gastroenterology}

Case Rep Gastroenterol 2017;11:305-311

(c) 2017 The Author(s). Published by S. Karger AG, Basel www.karger.com/crg

Sugiura et al.: Successful Treatment for Chronic Hepatitis C-Autoimmune Hepatitis Overlap Syndrome due to Daclatasvir and Asunaprevir

(AST and ALT) and HCV-RNA (Table 1). Additionally, increased total protein, gamma globulin fraction, and immunoglobulin G (IgG) and a high titer of ANA (1:320) were detected, suggesting the possibility of AIH (Table 1). Abdominal ultrasonography showed no intrahepatic mass, portal hypertension, or splenomegaly. Liver biopsy revealed infiltration of lymphocytes and plasma cells in Glisson's capsule and moderate-to-severe interface hepatitis with mild bridging fibrosis (Fig. 1), which is compatible with AIH rather than chronic hepatitis C. No hepatocyte ballooning, perisinusoidal fibrosis, or bile duct injury were found.

Since pre-treatment AIH score was calculated as 10 according to the scoring system proposed by the International Autoimmune Hepatitis Group, this patient was considered to have chronic hepatitis C-AIH overlap syndrome. We started oral administration of prednisolone (PSL, $30 \mathrm{mg} /$ day), and serum ALT levels decreased once but increased again. We were concerned about the possibility that IFN-based antiviral therapies may worsen AIH. Following approved prescription in Japan, we started daclatasvir (DSV, $60 \mathrm{mg} /$ day) and asunaprevir (ASV, $200 \mathrm{mg} /$ day) (Fig. 2). His HCV strain had no resistance mutation of domain to NS5A and NS3/4. After starting the DAA treatment, circulating HCV-RNA decreased rapidly and became undetectable at 6 weeks of the treatment. Serum ALT levels improved simultaneously, so PSL was tapered and stopped (Fig. 2). Adverse effects were not found during the DAA treatment. He is now being observed after 24 weeks' DAA treatment, and serum HCVRNA remains negative with no rebound of ALT, IgG, and ANA.

\section{Discussion}

In chronic hepatitis $\mathrm{C}$ patients having a high titer of ANA and hypergammaglobulinemia, the coexistence of AIH should be considered. Chronic hepatitis C-AIH overlap syndrome is divided into two clinical entities, virus-predominant and autoimmune-predominant types [5]. In the autoimmune-predominant type, the titer of ANA is equal to or more than 1:320 and liver histology shows interface hepatitis, lobular hepatitis, broad areas of hepatocyte collapse, and plasma cell infiltration. In the virus-predominant type, portal lymphoid cell follicle, steatosis, and bile duct injury were observed. The combination of portal lymphoid aggregates and steatosis was found to have $91 \%$ specificity of chronic hepatitis $\mathrm{C}$, whereas the pattern of lymphoplasmacytic portal, interface, or acinar hepatitis had $81 \%$ specificity for AIH. In the present case, high ANA titer (1:320) and the presence of typical histological findings, such as infiltration of lymphocytes/plasma cells in liver parenchyma and moderateto-severe interface hepatitis, prompted us to make a diagnosis of autoimmune-predominant chronic hepatitis C-AIH overlap syndrome.

Therapeutic strategies for chronic hepatitis C-AIH overlap syndrome have not been established. One management concept is to estimate the predominant entity in order to select the appropriate therapy, i.e., corticosteroid monotherapy or corticosteroid/azathioprine combination for the autoimmune-predominant type and IFN-based antiviral therapies for the virus-predominant type. Since the present case fulfilled the criteria of AIH according to the AIH scoring system, corticosteroid administration was commenced but its effect was minimal.

IFN treatment may exacerbate AIH. Actually, aggravated jaundice was reported in a patient with chronic hepatitis C-AIH overlap syndrome treated with IFN [4]. On the contrary, 
DAA is assumed to have a lower risk of worsened autoimmune disorders compared with IFN therapy. Immunoallergic hepatitis and skin eruption have been reported as adverse effects of DSV/ASV combination therapy [6], but the treatment was accomplished without any adverse effects in this patient. Furthermore, ANA and IgG returned within normal ranges after the DAA treatment regardless of the discontinuation of corticosteroid. Reductions in ANA and IgG after HCV eradication may indicate the influence of HCV to autoimmune responses.

In conclusion, DAA appears to be effective and safe for chronic hepatitis C-AIH overlap syndrome. Further studies are needed to verify the usefulness of DAA for this disease.

\section{Statement of Ethics}

The authors have no ethical conflicts to disclose. Informed consent was obtained from the patient.

\section{Disclosure Statement}

The authors declare no financial conflicts of interest.

\section{References}

1 Rigopoulou EI, Zachou K, Gatselis N, Koukoulis GK, Dalekos GN: Autoimmune hepatitis in patients with chronic HBV and HCV infections: patterns of clinical characteristics, disease progression and outcome. Ann Hepatol 2013;13:127-135.

72 Cacoub P, Gragnani L, Comarmond C, Zignego AL: Extrahepatic manifestations of chronic hepatitis C virus infection. Dig Liver Dis 2014;46:S165-S173.

Koike K, Moriya K, Ishibashi K, Yotsuyanagi H, Shintani Y, Fujie H, Kurokawa K, et al: Sialadenitis histologically resembling Sjogren syndrome in mice transgenic for hepatitis $\mathrm{C}$ virus envelope genes. Proc Natl Acad Sci USA 1997;94:233-236.

4 Sezaki H, Arase Y, Tsubota A, Suzuki Y, Kobayashi M, Saitoh S, Suzuki F, et al: Type C-chronic hepatitis patients who had autoimmune phenomenon and developed jaundice during interferon therapy. J Gastroenterol 2003;38:493-500.

5 Czaja AJ: The variant forms of autoimmune hepatitis. Ann Intern Med 1996;125:588-598.

6 Fujii Y, Uchida Y, Mochida S: Drug-induced immunoallergic hepatitis during combination therapy with daclatasvir and asunaprevir. Hepatology 2015;61:400-401. 


\section{Case Reports in Gastroenterology}
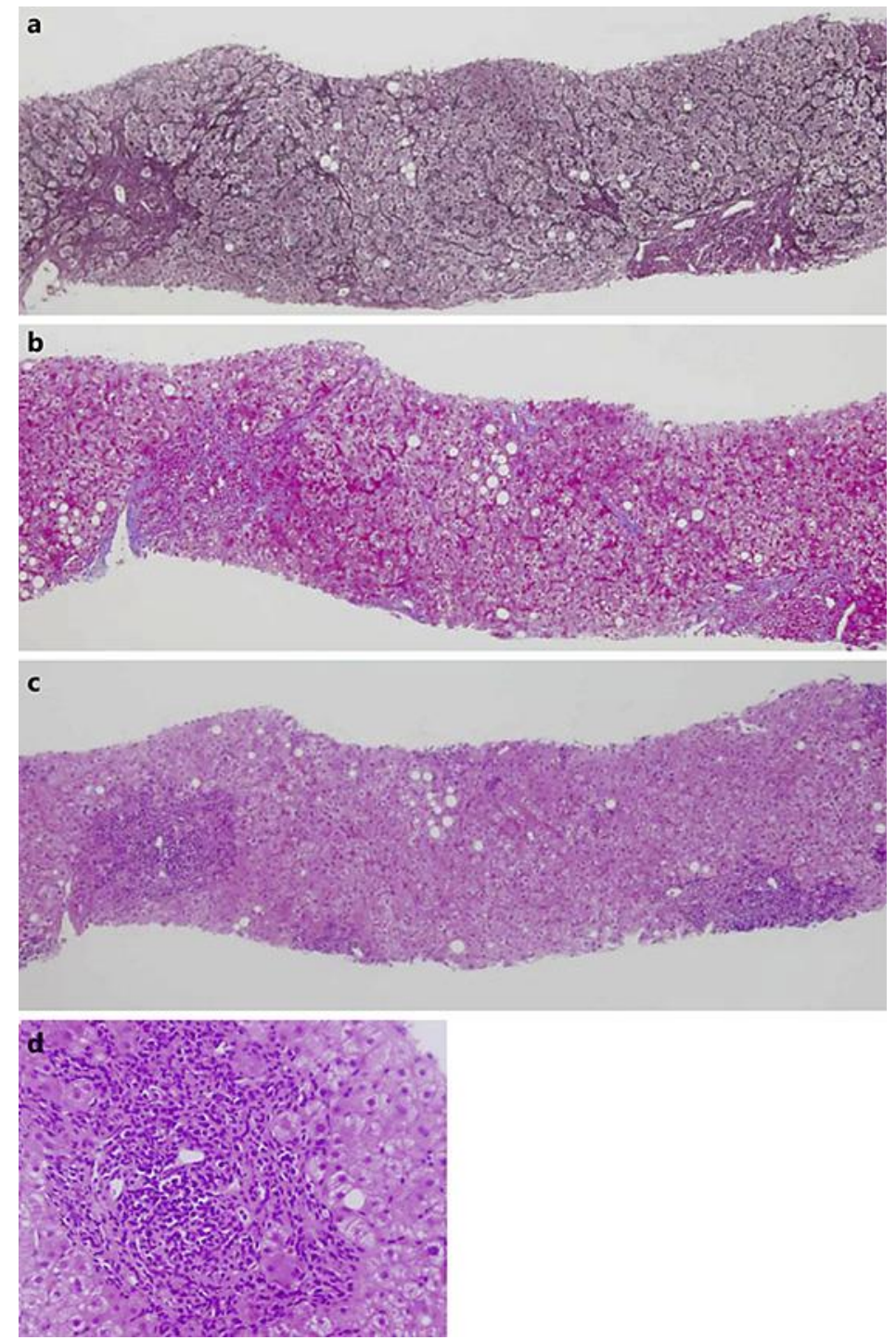

Fig. 1. Liver histology of this patient. a, b Silver (a) and Azan-Mallory (b) staining. Mild bridging fibrosis was seen. c, d Hematoxylin \& eosin staining. Piecemeal necrosis, interface hepatitis, massive infiltration of lymphocytes, and plasma cells into the portal area were observed. 


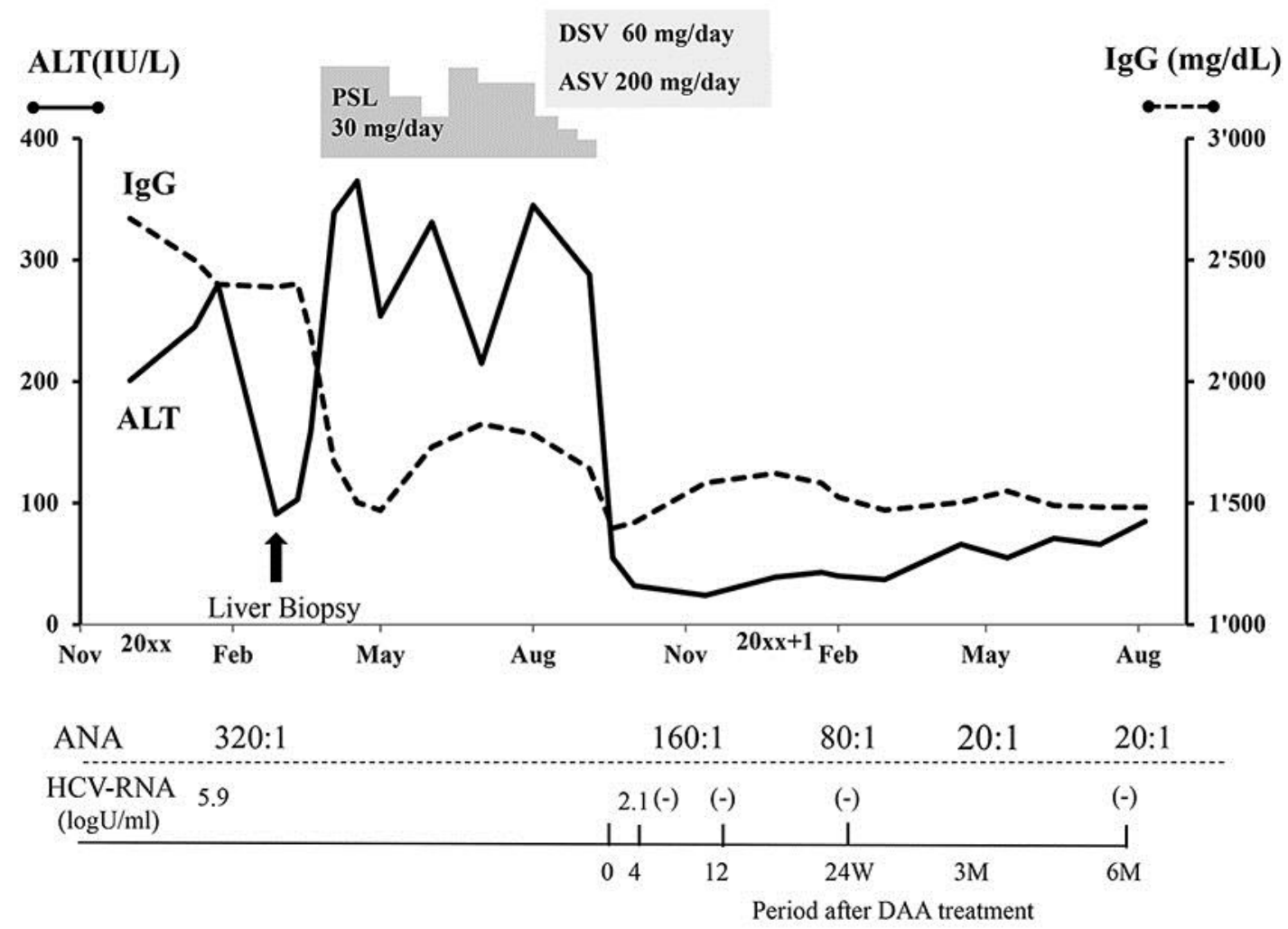

Fig. 2. Clinical course of our patient. ALT, alanine aminotransferase; PSL, prednisolone; DSV, daclatasvir; ASV, asunaprevir; IgG, immunoglobulin G; ANA, antinuclear antibody; HCV, hepatitis C virus. 
Sugiura et al.: Successful Treatment for Chronic Hepatitis C-Autoimmune Hepatitis

Overlap Syndrome due to Daclatasvir and Asunaprevir

Table 1. Laboratory data of our patient on admission

\begin{tabular}{lcclll}
\hline & Normal range & Patient & & Normal range & Patient \\
\hline White blood cell count, $/ \mu \mathrm{L}$ & $3,590-9,640$ & 5,770 & $\mathrm{Na}, \mathrm{mmol} / \mathrm{L}$ & $139-146$ & 140 \\
Hemoglobin, $\mathrm{g} / \mathrm{dL}$ & $13.2-17.2$ & 16.5 & $\mathrm{~K}, \mathrm{mmol} / \mathrm{L}$ & $3.7-4.8$ & 4.3 \\
Platelet count, $\times 10^{3} / \mu \mathrm{L}$ & $148-339$ & 143 & $\mathrm{Cl}, \mathrm{mmol} / \mathrm{L}$ & $101-109$ & 103 \\
Total protein, g/dL & $6.7-8.3$ & 8.5 & HBsAg & $(-)$ & $(-)$ \\
Albumin, $/ \mathrm{dL}$ & $3.8-5.3$ & 4.2 & Anti-HBs & $(-)$ & $(-)$ \\
Bilirubin, mg/dL & $0.3-1.2$ & 0.5 & Anti-HBc & $(-)$ & $(-)$ \\
AST, IU/L & $12-41$ & 166 & Anti-HCV antibody & $(-)$ & $(+)$ \\
ALT, IU/L & $7-45$ & 201 & HCV-RNA, logU/mL & $(-)$ & 5.9 \\
ALP, IU/L & $90-298$ & 238 & HCV genotype & & $1 \mathrm{~b}$ \\
$\gamma$ GTP, IU/L & $4-50$ & 343 & FANA & $(-)$ & $1: 320$ \\
LDH, IU/L & $90-230$ & 218 & AMA & $(-)$ & $(-)$ \\
BUN, mg/dL & $8-21$ & 11.2 & IgG, mg/dL & $870-1,700$ & 2,671 \\
Creatinine, mg/dL & $0.8-1.3$ & 0.78 & & & \\
\hline
\end{tabular}

AST, aspartate aminotransferase; ALT, alanine aminotransferase; ALP, alkaline phosphatase; $\gamma \mathrm{GTP}$, gammaglutamyltransferase; LDH, lactate dehydrogenase; BUN, blood urea nitrogen; HCV, hepatitis C virus; FANA, fluorescent antinuclear antibody; AMA, antimitochondrial antibody; IgG, immunoglobulin G. 